\title{
Texas nutrition environment assessment of retail food stores (TxNEA-S): development and evaluation
}

\author{
Christian T Gloria* and Mary A Steinhardt \\ Department of Kinesiology and Health Education, College of Education, The University of Texas at Austin, \\ 1 University Station D3700, Austin, TX 78712-0306, USA
}

Submitted 27 September 2009: Accepted 22 April 2010: First published online 11 June 2010

\begin{abstract}
Objective: Current nutrition environment instruments are typically designed to measure a small number of healthy foods based on national trends. They lack the depth to accurately measure the unique dietary choices of subpopulations, such as Texas consumers whose food preferences are influenced by Hispanic/Latino culture. Thus the purposes of the present study were to: (i) develop a comprehensive observational tool to measure the availability of healthy foods from retail stores in Texas; and (ii) conduct a pilot test to examine the tool's reliability, as well as differences in the availability of healthy foods in stores between high- and low-income neighbourhoods.

Design: Grocery and convenience stores were assessed for availability of healthy foods. Reliability was calculated using percentage agreement, and differences in availability were examined using 2 (store type) $\times 2$ (neighbourhood income) ANOVA.

Setting: One high-income and one low-income neighbourhood in Austin, Texas. Subjects: A sample of thirty-eight stores comprising twenty-five convenience stores and thirteen grocery stores.

Results: The low-income neighbourhood had $324 \%$ more convenience stores and $56 \%$ fewer grocery stores than the high-income neighbourhood. High inter-rater (mean $=0.95)$ and test-retest reliability $($ mean $=0.92)$ and a significant interaction $(P=0 \cdot 028)$ between store type and neighbourhood income were found.

Conclusions: The TxNEA-S tool includes 106 healthy food items, such as fruits, vegetables, dairy, proteins and grains. The tool is reliable and face validity is affirmed by the Texas Department of Health. Grocery stores have more healthy foods than convenience stores, and high-income grocery stores offer more healthy foods than low-income grocery stores.
\end{abstract}

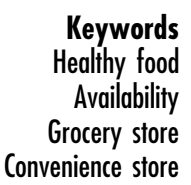

The obesity epidemic is one of the leading national health concerns due to its serious consequences and rapidly increasing prevalence in the USA ${ }^{(1-3)}$. Currently, about $66 \%$ of US adults and $32 \%$ of children and adolescents are either overweight or obese ${ }^{(4,5)}$. Similar trends are also experienced in Texas ${ }^{(6,7)}$, which was ranked as the fifth unhealthiest state in the nation ${ }^{(8)}$. If current patterns continue, $75 \%$ of Texas adults could become overweight or obese by 2040 , and health-care costs would quadruple from \$US 10.5 billion to over \$US 39 billion $^{(9)}$.

Individuals can only be as healthy as the community in which they reside ${ }^{(10,11)}$. Simply educating individuals and increasing awareness regarding the importance of healthy eating cannot effectively change behaviour and promote healthier lifestyles if their neighbourhoods fail to provide healthy food options. In order to improve health, it is imperative to improve the surrounding food environment. Organizations such as the Centers for Disease
Control and Prevention, the Institute of Medicine, the International Obesity Task Force and the WHO insist that environmental interventions are the most effective strategies for positively 'shifting the curve' and creating population-wide improvements in dietary intake and weight status ${ }^{(12-16)}$.

A growing body of research suggests that the food environment - the presence of food outlets and the available food products therein - influences consumer eating behaviour and contributes to overweight and obesity in the USA and around the world ${ }^{(11,17-22)}$. Glanz et $a l^{(11)}$ identified 'nutrition environments' as having the highest priority in research as they are the least understood yet could have the greatest impact on overweight and obesity. Research suggests that dietary intake is the main determinant of obesity and a greater predictor of weight outcome as compared with physical activity and energy expenditure ${ }^{(23,24)}$. Greater availability of healthy 
foods (e.g. fruits, vegetables, low-fat dairy) within neighbourhoods is associated with greater consumption of such healthy foods among the neighbourhood residents ${ }^{(13,25-31)}$. Alternatively, a similar pattern is observed with the presence of unhealthy foods (e.g. soft drinks, potato chips); greater availability of unhealthy food products is associated with greater consumer intake of such unhealthy items, which in turn may lead to poor health and diminished quality of life ${ }^{(32,33)}$.

The availability of healthy foods appears to be associated with neighbourhood income and the presence of certain stores. Low-income neighbourhoods have significantly fewer grocery stores and more convenience stores as compared with high-income neighbourhoods, and grocery stores offer greater amounts of healthy foods than convenience stores ${ }^{(34-36)}$. Experts believe that the lack of availability of healthy foods contributes to a higher incidence of overweight and obesity in lower-income populations $^{(37-40)}$.

A number of instruments have been developed to evaluate the availability of healthy foods within nutrition environments ${ }^{(35,36,38,41-49)}$. Some of these measures obtained reliability scores ranging from low to good ${ }^{(36,41-45)}$, while others did not report the reliability of their tools ${ }^{(35,38,46-49)}$. Furthermore, some of these instruments present limitations such as having only a small number of healthy food items to observe (five to thirty-nine items), which were typically selected according to consumer trends based on the general US population ${ }^{(41-45,47,49)}$. The limited number of items observed by such tools consequently ignores a large range of healthy foods recommended by the Dietary Guidelines for Americans $^{(50)}$, such as soya milk or cheese, beans or legumes, assorted grains, and canned/frozen fruits and vegetables.

According to a panel of dietitians, nutritionists and public health professionals from the Division of Nutrition, Physical Activity, and Obesity Prevention (NPAOP) of the Texas Department of State Health Services, these nutrition environment instruments not only need an increase in the number of items observed, but they also overlook and inadequately measure the distinct differences between different subgroups and cultures of the US population. For instance, the dietary preferences of Texas residents having a strong Hispanic or Latino influence vary distinctly from the dietary preferences of residents from other states; $36 \%$ of Texas residents are of Hispanic or Latino origin, as compared with the national average of $15 \%{ }^{51)}$. Therefore, the NPAOP collaborated with the researchers to develop the Texas Nutrition Environment Assessment of Retail Food Stores (TxNEA-S) tool, which was designed to expand the number of foods observed, as well as to more accurately capture the dietary preferences of the Texas population. With the instrument's greater depth and emphasis towards the Texas food culture, the TxNEA-S tool could provide greater understanding of how the nutrition environment affects the diet and health of Texas residents.
Therefore the purposes of the present study were to: (i) develop a comprehensive observational tool to measure the availability of healthy foods from grocery and convenience stores located in the State of Texas; and (ii) conduct a pilot test to examine the tool's inter-rater and test-retest reliability, as well as differences in the availability of healthy foods from grocery and convenience stores between high- and low-income neighbourhoods. It was hypothesized that grocery stores would have greater availability of healthy foods than convenience stores, and that stores from high-income neighbourhoods would have greater availability of healthy foods than stores from lowincome neighbourhoods.

\section{Methods}

\section{Development of TxNEA-S tool}

The NPAOP developed the TxNEA-S tool, which was adapted from the instrument Nutrition Environment Measures Survey in Stores (NEMS-S) ${ }^{(42)}$. While the NEMS-S was an acceptable tool for observing the dietary preferences of the average US consumer, the NPAOP believed that the items of the NEMS-S tool could be strengthened to more comprehensively observe the food choices of the Texas population. Thus, the list of food items was modified and expanded to include a large number of additional products such as mangoes, collard greens, rice, beans/legumes, tortillas, yoghurts and cheeses. The list of healthy foods was determined by a team of dietitians, nutritionists and public health professionals from the eight regional offices of the Texas $\mathrm{NPAOP}^{(52)}$. One food category that was not included in the TxNEA-S tool was meat products, as the NPAOP believed that Americans already consume greater than recommended amounts of such items; instead, the tool measured the less consumed yet more recommended sources of protein such as beans and legumes. Additionally, the TxNEA-S also measured the availability of canned and frozen alternatives to account for low-income neighbourhoods which have been shown to have limited or no resources for fresh products ${ }^{(38)}$. A total of 106 healthy foods were measured by the TxNEA-S tool from a variety of food categories recommended by the Dietary Guidelines for Americans ${ }^{(50)}$ (see Appendix). The TxNEA-S tool was used for assessments of both convenience and grocery stores. A copy of the tool is available from the corresponding author.

\section{Neigbbourbood selection}

The study was conducted in one low- and one highincome neighbourhood located in central Austin, Texas. Each neighbourhood was composed of two adjacent zipcode areas. Zip-code areas were used as they are larger than census tracts and thus captured more stores per neighbourhood. In addition, it was found that a single 


\begin{tabular}{|c|c|}
\hline A & $\leq$ \$US11 250 \\
\hline B & \$US11 667-\$US26 152 \\
\hline C & \$US26 202-\$US34 545 \\
\hline D & \$US34 596-\$US44 375 \\
\hline E & \$US44476-\$US58 929 \\
\hline F & \$US59180-\$US83950 \\
\hline G & $\geq \$$ SUS84847 \\
\hline
\end{tabular}

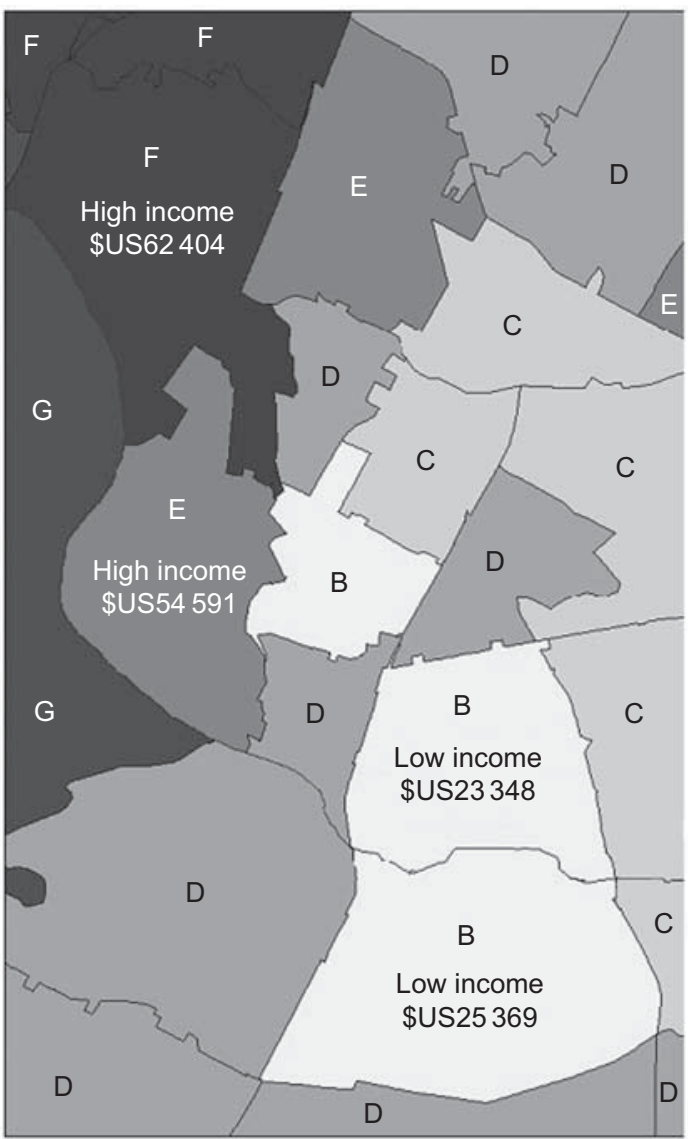

Fig. 1 Categories of median household income per zip-code area, central Austin, Texas

zip-code did not offer enough stores, and so neighbourhood size was doubled by the combination of two adjacent zip-code areas. The US Census ${ }^{(53)}$ was used to determine median household income per zip-code area, with income divided into seven categories of median household income as illustrated by the Census geographic information mapping (see Fig. 1) ${ }^{(54)}$. Two zip-code areas with the lowest median household income were selected to represent the low-income neighbourhood, and then contrasted against two zip-code areas with higher income. This neighbourhood selection method was adopted from Glanz et al. ${ }^{(42)}$, 'to maximize the ability to contrast food outlet types between neighbourhoods with differing levels of income'. Communities within the highest range of income were excluded, considering the relatively small proportion of these residents. Therefore, to represent the high-income neighbourhood, the second and third most affluent zipcode areas were selected.

As shown in Fig. 1, the low-income neighbourhood consisted of two zip-code areas with median household incomes ranging from \$US 23348 to \$US 25369, which fell below the Texas (\$US 39927) and US (\$US 41994) median household incomes ${ }^{(53)}$. In contrast, the median household incomes of the two zip-code areas within the high-income neighbourhood ranged from \$US 54591 to
\$US 62 404, which were greater than the state and national median household incomes. Two categories of income approximately a \$US 30000 gap - separated the low- and high-income neighbourhoods. The remaining and unselected low-income zip-code area seen in the centre of Fig. 1 is a university setting with primarily student residents; therefore it was not considered for the neighbourhood sample selection. Each neighbourhood was independently located within the eastern or western section of the city, which minimized the potential overlap in residents' access to stores in the contrasting neighbourhood. The low-income neighbourhood had a larger population (with 63195 residents) as compared with the high-income neighbourhood's 43644 residents. However, despite the disparities between the low- and high-income neighbourhoods, some similarities were still accounted for to ensure a balanced design in order to conduct valid comparisons. For instance, the lowand high-income neighbourhoods were $100 \%$ urban, residential communities and had similar land sizes (12.6 and $13 \cdot 5$ square miles, respectively).

\section{Definition and selection of stores}

A list of stores within the neighbourhood samples was collected from the city's Consumer Health Services, printed Yellow Pages and online directories, and then 
Table 1 Cross-tabulation of actual and sample ratios of store types within neighbourhood samples, central Austin, Texas

\begin{tabular}{lccc}
\hline & \multicolumn{3}{c}{ Actual prevalence of store type within neighbourhood sample } \\
\cline { 2 - 4 } & Convenience store & Grocery store & Total \\
\hline Low-income neighbourhood & 55 & 4 & 59 \\
High-income neighbourhood & 17 & Grocery store & 26 \\
& \multicolumn{2}{c}{ Study sample size by store type and neighbourhood income } \\
\cline { 2 - 4 } Low-income neighbourhood & Convenience store & 4 & 17 \\
High-income neighbourhood & 13 & 9 & 21 \\
\hline
\end{tabular}

verified through on-site visitations in January 2008. Stores that were inaccessible to the general public (e.g. within worksites, schools or private facilities) were not included. Specialty stores (e.g. bakeries or liquor stores) were also excluded considering their limited range of products.

The stores selected for the study were classified into two main categories: convenience stores and grocery stores. Convenience stores were defined as food outlets having limited options and primarily stocking items intended for immediate consumption (e.g. potato chips, snack items, soft drinks). Grocery stores were defined as food outlets offering a full range of items from all food categories, above and beyond what convenience stores offer. A consistent distinguishing feature of grocery stores was the availability of fresh/raw products which require preparation and/or cooking (e.g. fruits, vegetables and raw meat). These definitions were obtained from a NEMS-S ${ }^{(42)}$ research/training specialist via email correspondence as their published work did not discuss how convenience stores and grocery stores were operationalized (E. Davis, personal communication, April 2008).

A total of eighty-five stores were found within the selected neighbourhoods (see Table 1). For data collection, all existing grocery stores in both neighbourhoods were selected, and a smaller random sample of convenience stores was selected out of seventy-two total convenience stores due to limited resources. From the originally selected forty-store sample, one low-income convenience store went out of business and one highincome convenience store withdrew from participation, leaving a total sample of thirty-eight stores. As shown on Table 1, the low-income neighbourhood sample had thirteen convenience and four grocery stores, while the high-income neighbourhood sample had twelve convenience and nine grocery stores. The obtained sample size within each neighbourhood meets the minimum size discussed by Glanz et $a l^{(42)}$ of at least fifteen stores per neighbourhood.

\section{Phase I: rater training and TxNEA-S tool refinement}

The purposes of Phase I of the study were to: (i) introduce the newly developed TxNEA-S tool to the raters; (ii) provide data collection training; (iii) conduct practice store assessments; and (iv) further refine the TxNEA-S tool according to rater feedback.

The raters were twenty-one senior undergraduate nutrition majors from the University of Texas at Austin. Rater training consisted of four $1 \mathrm{~h}$ classroom instruction sessions which included PowerPoint presentations, itemby-item discussions of tool content, and instructions regarding observation and data collection procedures. Classroom instructions were followed by $3 \mathrm{~h}$ of practice store assessments at randomly selected stores. After each training session, rater feedback was gathered to identify data collection experiences and recommendations for improvement. Training and fieldwork protocols were guided by the NEMS-S manual ${ }^{(55)}$.

Initial evaluations revealed that the original draft of the TxNEA-S tool was excessively lengthy and required an unfeasible amount of time to complete; therefore, the tool was revised and redesigned accordingly. For example, the measure to record item shelf-space was removed from the tool as raters found the task to be time-consuming and difficult to assess accurately. To reduce evaluation time, items of least importance were identified and removed, and the tool was formatted to require less writing. The tool was continually revised until raters believed that it was manageable and ready for pilot evaluation. Approximately ten revisions were made, which reduced the original 19-page tool to 12 pages, and decreased evaluation time from initially over $180 \mathrm{~min}$ to an average of $73 \mathrm{~min}$ for grocery stores and $19 \mathrm{~min}$ for convenience stores. This phase of the project lasted one academic semester.

\section{Phase II: pilot evaluation of the TxNEA-S tool}

The purpose of Phase II of the study was to pilot test the TxNEA-S tool for inter-rater and test-retest reliability, using the same raters from Phase I. The collected data would also be used for comparing the availability of healthy foods in grocery and convenience stores between low- and high-income neighbourhoods.

A subsample of the total sample size (see Table 1) was used for reliability testing due to limited resources. Grocery stores were prioritized in the selection of samples for reliability testing, considering that: (i) the same survey was used regardless of store type; and (ii) grocery stores have substantially more food options. Inter-rater reliability 
assessment was calculated using all thirteen grocery stores and six randomly selected convenience stores. Test-retest reliability was computed using a convenience sample of ten grocery stores. These subsamples satisfy the recommendation that subsample size for reliability testing be at least $10-20 \%$ of the total sample size ${ }^{(56)}$.

To evaluate inter-rater reliability, two data collectors were randomly assigned to each store with instructions to simultaneously complete the TxNEA-S tool. To ensure independence between the two raters, they were instructed to begin assessments from opposite ends of the tool (one rater started on the first page of the tool, while the other started on the last page). Item-by-item agreement between the two raters was compared, and percentage agreement - the frequency of correctly matched responses divided by the total number of observations ${ }^{(57)}$ - was calculated using Microsoft ${ }^{\circledR}$ Office Excel 2007 (Microsoft Corp., Redmond, WA, USA). To examine testretest reliability, one of the two raters was randomly selected and directed to re-evaluate the same store within four weeks of the initial observation date. Item-by-item agreement between initial and follow-up observations was compared, and percentage agreement was calculated using the Excel software.

Finally, a $2 \times 2$ ANOVA was used to examine mean comparisons of the availability of healthy foods between store types (grocery and convenience stores) and neighbourhood incomes (low and high), using the SPSS statistical software package version 16 (SPSS Inc., Chicago, IL, USA). Data from the total sample size (see Table 1) were used for this analysis, and the availability score was determined by the percentage value (out of the total 106 tool items) observed as present in the store during data collection.

\section{Results}

The cross-tabulation of all grocery and convenience stores within the neighbourhood samples revealed that the low-income neighbourhood had over three times as many convenience stores and less than half as many grocery stores, as compared with the high-income neighbourhood (see Table 1). According to Fisher's Exact Probability Test, there was a statistically significant association between the frequency of store type and neighbourhood income $(P=0 \cdot 002$, two-tailed).

Table 2 shows the inter-rater and test-retest reliability results. Rates of inter-rater agreement on the availability measure ranged from moderate (79\%) to very high (100\%), with a mean of 95 (SD 6) \%. Test-retest reliability scores on availability yielded similarly strong findings, ranging from $80 \%$ to $100 \%$, with a mean of 92 (SD 6) $\%$.

Figure 2 shows a histogram of the mean comparisons of the availability of healthy foods between store type and neighbourhood income. It illustrates that neighbourhood income has a positive relationship with the availability of
Table 2 Inter-rater and test-retest reliability scores for the TxNEA$\mathrm{S}$ tool, central Austin, Texas

\begin{tabular}{|c|c|c|}
\hline Store type & Inter-rater & Test-retest \\
\hline Grocery* & 0.95 & 0.97 \\
\hline Grocery* & 1.00 & $0 \cdot 88$ \\
\hline Grocery* & 0.93 & 0.99 \\
\hline Grocery* & 0.90 & 0.91 \\
\hline Groceryt & 0.88 & 0.92 \\
\hline Grocery† & $0 \cdot 86$ & 0.92 \\
\hline Groceryt & 0.79 & $0 \cdot 88$ \\
\hline Grocery† & $0 \cdot 88$ & 0.91 \\
\hline Grocery† & 0.99 & $0 \cdot 80$ \\
\hline Groceryt & $1 \cdot 00$ & $1 \cdot 00$ \\
\hline Grocery† & $1 \cdot 00$ & \\
\hline Grocery† & 0.97 & \\
\hline Groceryt & $1 \cdot 00$ & \\
\hline Convenience* & $1 \cdot 00$ & \\
\hline Convenience* & 0.99 & \\
\hline Convenience $^{*}$ & $1 \cdot 00$ & \\
\hline Conveniencet & 0.95 & \\
\hline Conveniencet & 0.99 & \\
\hline Conveniencet & 0.99 & \\
\hline Mean & 0.95 & 0.92 \\
\hline SD & 0.06 & 0.06 \\
\hline
\end{tabular}

TxNEA-S, Texas Nutrition Environment Assessment of Retail Food Stores. *Low-income neighbourhood. tHigh-income neighbourhood.

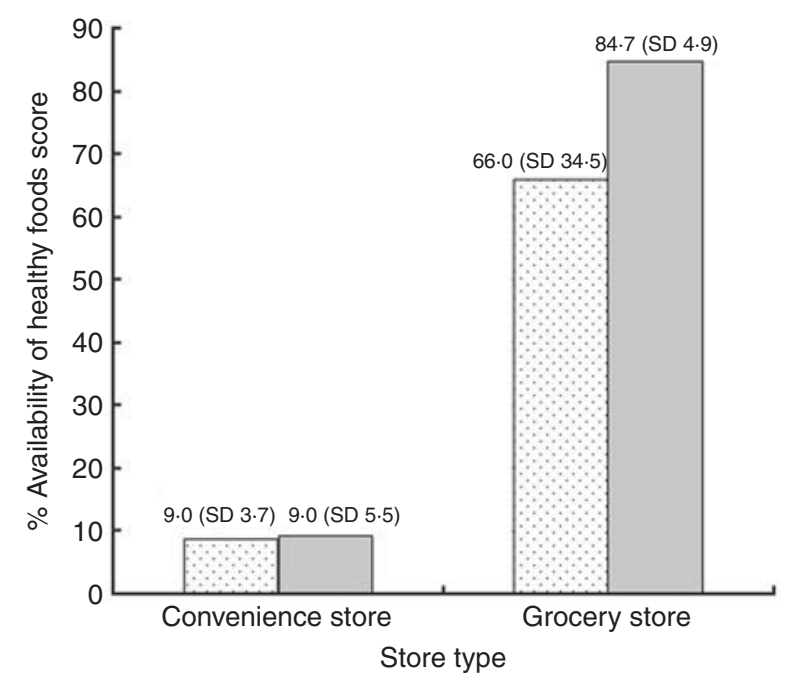

Fig. 2 Comparison of means and standard deviations of the availability of healthy foods between store type and neighbourhood income ( $\square$, low-income neighbourhood; $\square$, high-income neighbourhood), central Austin, Texas. Note: \% Availability of healthy foods score $=$ (no. of healthy foods observed $/ 106$ total items) $\times 100$

healthy foods in grocery stores; however, neighbourhood income appears to have no association with the availability of healthy foods in convenience stores. The $2 \times 2$ ANOVA of store type (grocery and convenience stores) and neighbourhood income (low- and high-income) on availability of healthy foods found a significant relationship with store type $\left(F(1,34)=269 \cdot 66, P<0 \cdot 001, \eta_{p}{ }^{2}=\right.$ $0 \cdot 888)$ and a significant relationship with neighbourhood income $\left(F(1,34)=5 \cdot 39, P=0 \cdot 026, \eta_{p}^{2}=0 \cdot 137\right)$. A statistically 
significant interaction was also found for store type and neighbourhood income $\left(F(1,34)=5 \cdot 26, P=0 \cdot 028, \eta_{p}{ }^{2}=\right.$ $0 \cdot 134)$.

A limitation to this analysis was that the assumptions of homogeneity and normality were not satisfied due to one unusual case: a small grocery store from the low-income neighbourhood. Out of the four observed grocery stores from the low-income neighbourhood, three were large chain grocery stores but one was a smaller local grocery store. Based on Glanz et al. ${ }^{(42)}$, small grocery stores have one or two cash registers, while large grocery stores have three or more. The small local grocery store had substantially less availability of healthy foods as compared with the three larger stores, which pulled and skewed the group mean. This store was not removed in the analysis because it: (i) matched the operational definition of a grocery store; (ii) was not considered an outlier as it falls within three standard deviations; and (iii) was expected to appear in the sample since small local grocery stores are known to exist, particularly in low-income neighbourhoods.

When this unusual case was removed from the data set, all statistical test assumptions were satisfied but the $2 \times 2$ ANOVA produced somewhat dissimilar results. As expected, a significant relationship was found with store type $\left(F(1,33)=1525 \cdot 70, P<0 \cdot 001, \eta_{p}^{2}=0 \cdot 979\right)$. However, the relationship with neighbourhood income was found to be statistically non-significant $(F(1,33)=0 \cdot 218, P=0.643$, $\left.\eta_{p}{ }^{2}=0.007\right)$ and the interaction for store type and neighbourhood income was also found to be statistically non-significant $\left(F(1,33)=0 \cdot 166, P=0 \cdot 686, \eta_{p}^{2}=0 \cdot 005\right)$. Therefore, the prior reported statistically significant findings should be interpreted with this limitation in mind.

\section{Discussion}

Research suggests that nutrition environments - grocery and convenience stores, and the food products therein influence individual dietary consumption, weight status and subsequent health outcomes ${ }^{(11,17-22)}$. A number of nutrition environment instruments have been developed to observe the availability of healthy foods in retail stores $^{(35,36,38,41-49)}$, but these measures lack a comprehensive scope and the sensitivity required to effectively assess food choices from specific subgroups of the US population, such as Texas consumers whose dietary preferences are strongly influenced by Latino and Hispanic cultures. Therefore, the NPAOP collaborated with the researchers to develop the TxNEA-S tool, which was designed to effectively examine the availability of healthy foods in grocery and convenience stores in Texas.

In comparison to other instruments that produced low to good reliability scores ${ }^{(36,41-45)}$ or were not tested for reliability ${ }^{(35,38,46-49)}$, the TxNEA-S tool obtained moderate to very high inter-rater and test-retest reliability scores. The high inter-rater reliability scores indicate that the availability measure has a sound design and that the rater training protocol adequately prepares data collectors for accurate store assessments. The high test-retest reliability scores suggest limited change in the availability of the observed healthy foods over a period of several weeks; however, this finding may be inapplicable to convenience stores as test-retest reliability was examined only in grocery stores.

Neighbourhood income has a significant positive relationship with the availability of healthy foods in grocery stores, as data indicated that grocery stores from highincome neighbourhoods have greater availability of healthy foods than grocery stores from low-income neighbourhoods. However, neighbourhood income appears to have no relationship with the availability of healthy foods in convenience stores. This interaction between neighbourhood income and the availability of healthy foods from grocery and convenience stores did not support the proposed hypothesis that neighbourhood income would instead have a direct relationship with store type and the available healthy foods therein, as found by previous research $^{(42)}$. As shown in Fig. 2: (i) there is no difference in the availability of healthy foods between convenience stores regardless of neighbourhood income; (ii) grocery stores from low-income neighbourhoods offer greater availability of healthy foods than convenience stores from both lowand high-income neighbourhoods; and (iii) grocery stores from high-income neighbourhoods have greater availability of healthy foods as compared with grocery stores from low-income neighbourhoods as well as convenience stores from both low- and high-income neighbourhoods.

Although these findings are challenging to interpret because of the possible violations of the statistical assumptions of homogeneity and normality due to the influence of the unusual case (small local grocery store in the low-income neighbourhood) which nullified some of the initial significant findings, it is important to consider that this may be the reality of nutrition environments within low-income neighbourhoods. With increased sample size, investigators may find - and have found ${ }^{(42)}$ higher frequencies of small grocery stores. It is recommended that the sample size in each cell has at least ten stores, as not only does this allow for conducting stronger comparisons, it also maintains the robustness of the ANOVA test even under situations when violations of assumptions are experienced.

The cross-tabulation of the actual store frequencies within the neighbourhood samples revealed a large disparity in the convenience and grocery store ratios between low- and high-income neighbourhoods (see Table 1). The data show that the low-income neighbourhood had $227 \%$ more stores than the high-income neighbourhood. The low-income neighbourhood had $324 \%$ more convenience stores and 56\% fewer grocery stores, as compared with the high-income neighbourhood. These findings support previous research in that 
grocery stores are less prevalent while convenience stores are of greater numbers in low-income neighbourhoods $^{(34,36,38,40,58)}$. Even though lower-income residents have far greater access to convenience stores, this provides no additional benefit because of the very limited availability of healthy foods in such stores, especially fruits and vegetables ${ }^{(34,38,40)}$. Lower-income residents may actually be negatively affected by the omnipresence of convenience stores within their neighbourhoods, considering how they are less likely to own a vehicle, and so the proximity of stores may influence what stores they are more likely to visit. According to the US Census ${ }^{(53)}$, only about $59 \%$ of low-income residents own a vehicle as compared with $80 \%$ of high-income residents. If grocery stores in low-income neighbourhoods are over 3 miles apart while convenience stores are only 0.25 miles apart, as found in the present study, then it is likely that lowincome residents are obtaining most of their food from nearby convenience stores.

Future research should continue to examine the food environment, the disparities between neighbourhoods, and how these influence health behaviours and outcomes. This pilot study is one of the initial efforts to understand the impact of grocery and convenience stores on residents in the State of Texas ${ }^{(29)}$. Larger and more longitudinal studies are needed to further examine the availability of healthy foods in Texas and elsewhere, in order to identify disparities, aetiology of disease and opportunities for positive changes ${ }^{(59)}$.

Given that healthy food items (e.g. fruits, vegetables, low-fat dairy) are globally recognized from one location to another, the TxNEA-S tool may be adapted as needed and used at other locations within and outside the USA. If the TxNEA-S tool falls short of thoroughly assessing a specific food culture, additional modifications - such as simply adding and/or removing food items - may be necessary to maintain validity. This study and other research ${ }^{(49)}$ serve as testaments that making such modifications can be effectively done to more accurately examine a particular culture.

\section{Conclusions}

The purpose of the current pilot study was to develop the TxNEA-S observational tool which measured the availability of healthy foods from grocery and convenience stores located in the State of Texas. With respect to the Texas native food culture, the TxNEA-S tool includes 106 healthy food items from categories recommended by the Dietary Guidelines for Americans, such as fruits, vegetables, dairy, proteins and grains. The tool has sound and reliable measures as indicated by high inter-rater and test-retest reliability scores, and the face validity of the tool was affirmed by the Texas Department of State Health Services.

\section{Acknowledgements}

This project did not receive financial support from any funding agency in the public, commercial or non-profit sectors. There were no conflicts of interest. C.T.G. coordinated the study, managed the data collection process and prepared the manuscript. M.A.S. assisted with the data analyses and edited the manuscript. We would like to thank Lindsay Rodgers, MA, RD, LD, and Celeste Windham, MS, RD, LD, from the Texas Department of State Health Services, as well as Karina Loyo, PhD, from the City of Austin Health and Human Services, for their assistance in developing the TxNEA-S tool and the study methodology. We would also like to thank Monica Meadows, $\mathrm{PhD}, \mathrm{RD}$, LD, and her class of 2008 nutrition students for their contribution towards the tool refinement and the data collection process.

\section{References}

1. Centers for Disease Control and Prevention (2008) US obesity trends 1985-2007. http://www.cdc.gov/nccdphp/ dnpa/obesity/trend/maps/index.htm

2. World Health Organization (2003) Diet, Nutrition and the Prevention of Chronic Diseases. Report of a Joint WHO/FAO Expert Consultation. WHO Technical Report Series no. 916. Geneva: WHO.

3. Centers for Disease Control and Prevention (2009) Health consequences. Overweight and obesity. http:// www.cdc.gov/nccdphp/dnpa/obesity/consequences.htm

4. Ogden CL, Carroll MD, Curtin LR et al. (2006) Prevalence of overweight and obesity in the United States, 1999-2004. JAMA 295, 1549-1555.

5. Ogden CL, Carroll MD \& Flegal KM (2008) High body mass index for age among US children and adolescents, 2003-2006. JAMA 299, 2401-2405.

6. Centers for Disease Control and Prevention (2008) Behavioral risk factor surveillance system. Prevalence and trends data: Texas - 2007, overweight and obesity. Weight classification by body mass index (BMI). http://apps. nccd.cdc.gov/brfss/display.asp?cat $=$ OB\&yr $=2007 \& q k e y=$ 4409\&state $=$ TX

7. Eaton DK, Kann L, Kinchen S et al. (2008) Youth Risk Behavior Surveillance - United States, 2007. Surveillance Summaries. Atlanta, GA: Centers for Disease Control and Prevention.

8. American Public Health Association, Partnership for Prevention Advocacy (2008) America's health rankings: 2008 results. http://www.americashealthrankings.org/ 2008/results.html

9. Texas Department of State Health Services (2004) Executive summary. In The Burden of Overweight and Obesity in Texas, 2000-2040, pp. 5-47 [EJ Sanchez, editor]. Austin, TX: Texas Department of State Health Services.

10. Booth SL, Sallis JF, Ritenbaugh C et al. (2001) Environmental and societal factors affect food choice and physical activity: rationale, influences, and leverage points. Nutr Rev 59, 3 Pt 2, S21-S39.

11. Glanz K, Sallis JF, Saelens BE et al. (2005) Healthy nutrition environments: concepts and measures. Am J Health Promot 19, 330-333.

12. Farley T \& Cohen DA (2005) Prescription for a Healthy Nation: A New Approach to Improving our Lives by Fixing our Everyday World. Boston, MA: Beacon Press. 
13. Koplan JP \& Dietz WH (1999) Caloric imbalance and public health policy. JAMA 282, 1579-1581.

14. Koplan JP, Liverman CT, Kraak VI et al. (2005) Preventing childhood obesity: health in the balance: executive summary. J Am Diet Assoc 105, 131-138.

15. World Health Organization (2009) Global strategy on diet, physical activity and health. Diet and physical activity: a public health priority. http://www.who.int/ dietphysicalactivity/en/

16. Institute of Medicine (2001) Health and Behavior: The Interplay of Biological, Behavioral, and Societal Influences. Washington, DC: National Academy Press.

17. Booth KM, Pinkston MM \& Carlos-Poston WS (2005) Obesity and the built environment. J Am Diet Assoc 105, 110-117.

18. Cummins S \& Macintyre S (2006) Food environments and obesity - neighbourhood or nation? Int J Epidemiol 35 , 100-104.

19. Drewnowski A (2004) Obesity and the food environment: dietary energy density and diet costs. Am J Prev Med 27, 154-162.

20. Holsten JE (2009) Obesity and the community food environment: a systematic review. Public Health Nutr 12, 397-405.

21. Powell LM, Auld MC, Chaloupka FJ et al. (2007) Associations between access to food stores and adolescent body mass index. Am J Prev Med 33, 4 Suppl., S301-S307.

22. Morland K, Roux AVD \& Wing S (2006) Supermarkets, other food stores, and obesity: the Atherosclerosis Risk in Communities Study. Am J Prev Med 30, 333-339.

23. Swinburn BA, Jolle D, Kremer PJ et al. (2006) Estimating the effects of energy imbalance on changes in body weight in children. Am J Clin Nutr 83, 859-863.

24. Spiegelman BM \& Flier JS (2001) Obesity and the regulation of energy balance. Cell 104, 531-543.

25. Story M, Neumark-Sztainer D \& French S (2002) Individual and environmental influences on adolescent eating behaviors. J Am Diet Assoc 102, 3 Suppl., S40-S51.

26. Edmonds J, Baranowski T, Baranowski J et al. (2001) Ecological and socioeconomic correlates of fruit, juice, and vegetable consumption among African-American boys. Prev Med 32, 476-481.

27. Laraia BA, Siega-Riz AM, Kaufman JS et al. (2004) Proximity of supermarkets is positively associated with diet quality index for pregnancy. Prev Med 39, 869-875.

28. Morland K, Wing S \& Roux AD (2002) The contextual effect of the local food environment on residents' diets: the Atherosclerosis Risk in Communities Study. Am J Public Health 92, 1761-1767.

29. Jago R, Baranowski T, Baranowski JC et al. (2007) Distance to food stores, adolescent male fruit and vegetable consumption: mediation effects. Int J Behav Nutr Phys Act 4, 35.

30. French SA, Story M \& Jeffery RW (2001) Environmental influences on eating and physical activity. Annu Rev Public Health 22, 309-335.

31. Moore LV, Diex Roux AV, Nettleton JA et al. (2008) Associations of the local food environment with diet quality - a comparison of assessments based on surveys and geographic information systems. Am J Epidemiol 167, 917-924.

32. Timperio A, Ball K, Roberts R et al. (2003) Children's fruit and vegetable intake: associations with the neighbourhood food environment. Prev Med 46, 331-335.

33. Sallis JF \& Glanz K (2006) The role of built environments in physical activity, eating, and obesity in childhood. Future Child 16, 89-108.

34. Morland K, Wing S, Diez Roux A et al. (2002) Neighborhood characteristics associated with the location of food stores and food service places. Am J Prev Med 22, 23-29.
35. Bodor JN, Rose D, Farley TA et al. (2008) Neighbourhood fruit and vegetable availability and consumption: the role of small food stores in an urban environment. Public Health Nutr 11, 413-420.

36. Franco M, Diez Roux AV, Glass TA et al. (2008) Neighborhood characteristics and availability of healthy foods in Baltimore. Am J Prev Med 35, 561-567.

37. Block JP, Scribner RA \& DeSalvo KB (2004) Fast food, race/ ethnicity, and income: a geographic analysis. Am J Prev Med 27, 211-217.

38. Morland K \& Filomena S (2007) Disparities in the availability of fruits and vegetables between racially segregated urban neighbourhoods. Public Health Nutr 10, 1481-1489.

39. Turrell G, Hewitt B, Patterson C et al. (2002) Socioeconomic differences in food purchasing behaviour and suggested implications for diet-related health promotion. I Hum Nutr Diet 15, 355-364.

40. Galvez MP, Morland K, Raines C et al. (2008) Race and food store availability in an inner-city neighbourhood. Public Health Nutr 11, 624-631.

41. Liese AD, Weis KE, Pluto D et al. (2007) Food store types, availability, and cost of foods in a rural environment. $J \mathrm{Am}$ Diet Assoc 107, 1916-1923.

42. Glanz K, Sallis JF, Saelens BE et al. (2007) Nutrition environment measures survey in stores (NEMS-S): development and evaluation. Am J Prev Med 32, 282-289.

43. Cheadle A, Psaty B, Wagner E et al. (1990) Evaluating community-based nutrition programs: assessing the reliability of a survey of grocery store product displays. $\mathrm{Am} \mathrm{J}$ Public Health 80, 709-711.

44. Horowitz CR, Colson KA, Hebert PL et al. (2004) Barriers to buying healthy foods for people with diabetes: evidence of environmental disparities. Am J Public Health 94, 1549-1554.

45. Andreyeva T, Blumenthal DM, Schwartz MB et al. (2008) Availability and prices of foods across stores and neighborhoods: the case of New Haven, Connecticut. Health Aff $\mathbf{2 7}$, 1381-1388.

46. Sloane DC, Diamant AL, Lewis LB et al. (2003) Improving the nutritional resource environment for healthy living through community-based participatory research. J Gen Intern Med 18, 568-575.

47. Jetter KM \& Cassady DL (2006) The availability and cost of healthier food alternatives. Am J Prev Med 30, 38-44.

48. Donkin AJ, Dowler EA, Stevenson SJ et al. (2000) Mapping access to food in a deprived area: the development of price and availability indices. Public Health Nutr 3, 31-38.

49. Block D \& Kouba J (2006) A comparison of the availability and affordability of a market basket in two communities in the Chicago area. Public Health Nutr 9, 837-845.

50. US Department of Health and Human Services, US Department of Agriculture (2005) Dietary Guidelines for Americans, 2005, 6th ed. Washington, DC: USDA.

51. US Census Bureau (2007) Texas. State \& county quickfacts. http://quickfacts.census.gov/qfd/states/48000.html

52. Texas Department of State Health Services (2009) NPAOP regional nutritionists map. http://www.dshs.state.tx.us/ obesity/NPAOPregion.shtm

53. US Census Bureau (2000) Census 2000 demographic profile highlights. Fact sheet. http://factfinder.census.gov

54. US Census Bureau (2000) Thematic maps. Texas by 5-digit zip code tabulation area. http://tinyurl.com/ye6wj3q

55. Glanz K, Clawson M, Young M et al. (2006) Nutrition Environment Measures Training Manual. Atlanta, GA: Emory University.

56. Wimmer RD \& Dominick JR (2005) Mass Media Research: An Introduction, 8th ed. Belmont, CA: Thomson Wadsworth. 
57. Spata AV (2003) Research Methods in Psychology: Science and Diversity. New York: Wiley.

58. Powell LM, Slater S, Mirtcheva D et al. (2007) Food store availability and neighborhood characteristics in the United States. Prev Med 44, 189-195.
59. Giskes K, Kamphuis CBM, van Lenthe FJ et al. (2007) A systematic review of associations between environmental factors, energy and fat intakes among adults: is there evidence for environments that encourage obesogenic dietary intakes? Public Health Nutr 10, 1005-1017.

\section{Appendix}

List of bealthy food items observed by the TxNEA-S tool

\begin{tabular}{|c|c|c|c|}
\hline Fruits & Vegetables & Dairy & Proteins \\
\hline $\begin{array}{l}\text { Fresh apples } \\
\text { Fresh oranges } \\
\text { Fresh bananas } \\
\text { Fresh cantaloupes } \\
\text { Fresh grapes } \\
\text { Fresh honeydew melons } \\
\text { Fresh peaches } \\
\text { Fresh pears } \\
\text { Fresh strawberries } \\
\text { Fresh watermelons } \\
\text { Fresh grapefruits } \\
\text { Fresh mangoes } \\
\text { Fresh papayas } \\
\text { Ready-to-eat cut-up fruits } \\
\text { Canned light pears } \\
\text { Canned light mandarins } \\
\text { Canned light mixed fruits } \\
\text { Canned light peaches } \\
\text { Canned light pineapples } \\
\text { Frozen strawberries } \\
\text { Frozen peaches } \\
\text { Frozen blueberries } \\
\text { Frozen mangoes } \\
\text { Frozen mixed berries } \\
\text { Mixed fruits }\end{array}$ & $\begin{array}{l}\text { Fresh tomatoes } \\
\text { Fresh cucumbers } \\
\text { Fresh carrots } \\
\text { Fresh broccoli } \\
\text { Fresh lettuce } \\
\text { Fresh corn } \\
\text { Fresh celery } \\
\text { Fresh cabbage } \\
\text { Fresh cauliflower } \\
\text { Fresh avocados } \\
\text { Fresh greens } \\
\text { Fresh onion } \\
\text { Fresh squash } \\
\text { Fresh courgette } \\
\text { Ready-to-eat lettuce } \\
\text { Ready-to-eat baby carrots } \\
\text { Ready-to-eat cut-up vegetables } \\
\text { Canned corn } \\
\text { Canned green beans } \\
\text { Canned tomatoes } \\
\text { Canned peas } \\
\text { Canned mixed vegetables } \\
\text { Frozen corn } \\
\text { Frozen carrots } \\
\text { Frozen broccoli } \\
\text { Frozen green beans } \\
\text { Frozen spinach } \\
\text { Frozen peas } \\
\text { Frozen mixed vegetables }\end{array}$ & $\begin{array}{l}\text { Skimmed milk quart } \\
\text { Skimmed milk half } \\
\text { Skimmed milk gallon } \\
1 \% \text { milk quart } \\
1 \% \text { milk half } \\
1 \% \text { milk gallon } \\
\text { Lactose-free quart } \\
\text { Lactose-free half } \\
\text { Lactose-free gallon } \\
\text { Soya milk quart } \\
\text { Soya milk half } \\
\text { Soya milk gallon } \\
\text { Light flavoured yoghurt } 6-8 \mathrm{oz} \\
\text { Light flavoured yoghurt } 32 \mathrm{oz} \\
\text { Light plain yoghurt } 6-8 \mathrm{oz} \\
\text { Light plain yoghurt } 32 \mathrm{oz} \\
\text { Light cottage cheese } 16 \mathrm{oz} \\
\text { Light cottage cheese } 24 \mathrm{oz} \\
\text { Fat-free American cheese } \\
\text { Mozzarella } \\
\text { Fat-free Cheddar cheese } \\
\text { Low-fat Mexican cheese }\end{array}$ & $\begin{array}{l}\text { Grains } \\
\text { Wholegrain bread } \\
\text { Wholegrain bagels } \\
\text { Wholegrain English muffin } \\
\text { Wholegrain tortillas } \\
\text { Non-fat flour tortillas } \\
\text { Wholegrain hamburger buns } \\
\text { Wholegrain hotdog buns } \\
\text { Wholegrain dinner rolls } \\
\text { Plain toasted oats } \\
\text { Bran flakes with raisins } \\
\text { Plain bran flakes } \\
\text { Grape nuts } \\
\text { Plain shredded wheat } \\
\text { Whole-wheat pasta } \\
\text { Brown rice } \\
\text { Whole-wheat flour } \\
\text { Bulk whole-wheat pasta } \\
\text { Bulk brown rice } \\
\text { Bulk whole-wheat flour } \\
\text { Rolled oats }\end{array}$ \\
\hline
\end{tabular}

TxNEA-S, Texas Nutrition Environment Assessment of Retail Food Stores. 